\title{
Glycemic index of four traditional red pigmented rice
}

\author{
Batuagahge Don Rohitha Prasantha* \\ Department of Food Science and Technology, Faculty of Agriculture, University of Peradeniya, 20400, Peradeniya, Sri Lanka
}

\begin{abstract}
The in vivo glycemic response of selected four red pigmented traditional rice cultivars was assessed by determining the glycemic index (GI) using 12 healthy human subjects. Four cultivars of brown rice were Kaluheenati, Wedaheenati, Rathkaral and Madathawalu. According to the amylose content, rice cultivars studied were classified as high amylose rice. The highest amylose and available carbohydrate contents were observed in Kaluheenati (28.5 $\pm 0.5 \%)$ and Rathkaral (74.2 $\pm 0.6 \%)$ respectively. The amylose content of Wedaheenati was the lowest $(26.1 \pm 0.2 \%)$ while Rathkaral showed the highest (28 $\pm 0.2 \%)$. The GI of rice cultivars ranged from $52.5 \pm 1.5$ to $64.0 \pm 2.5 \%$. The Wedaheenati variety exhibited the lowest GI while Madathawalu exhibited the highest GI value.
\end{abstract}

\section{Introduction}

The per capita consumption of rice fluctuates around $114 \mathrm{~kg}$ per year, depending on the price of rice and wheat flour [1]. Rice comprises of $72-80 \%$ carbohydrates as starch. Other than starch, rice rich in many nutrients such as proteins, lipid, fiber, minerals and vitamins as well as some bioactive compounds and antioxidants [2]. Digestibility of the rice starch attributes to the properties of starch, including its crystallinity, granular structure and amylose: amylopectin ratio. The type of rice variety and type play an important role in determining the digestibility of starch and its Glycemic Index (GI). Like most of the other cereals, rice contains large amounts of rapidly digestible carbohydrates that may be detrimental to health as they raise glucose concentration in blood, which is crucial for diabetics [3]. In the Sri Lankan context, noncommunicable diseases (NCD) related to the diabetes mellitus have rapidly increased over the last two decades and it has become number one NCD leading cause of death in the nation.

Widely consumed type of rice is white pericarp rice in the world which is known as non-pigmented white rice. In addition, there are two other types of pigmented rice consumed in the world known as dark and light pigmented rice. Anthocyanin pigments are accumulated in different concentrations of the rice pericarp of pigmented rice. Therefore, raw rice kernels appear red or dark red in colors [4]. At present most of the traditional rice cultivars has become more popular among consumers due to their high nutrient value, dark pigmented pericarp and other functional properties of the rice grain. More than 300-400 different traditional rice cultivars are grown in the country [5]. These cultivars are highly diversified among each other with respect to unique nutrient, cooking and eating characteristics [6]. Most of the traditional rice cultivars have strong pericarp which is can't not easily removed during the rice milling. Most of the pigmented traditional rice cultivars are being used in the Ayurvedic medical treatments such as diabetes and cancers. The red rice has potential health benefits due to its high dietary fiber content and antioxidant properties which could help reduce the GI, thereby reducing the risk of type II diabetes [2]. Dietary fiber helps to delay the gastric emptying and absorption of carbohydrates and also by increasing satiety contributes to decrease the GI. Hence, the objective of this study is to investigate the effect of red pericarp traditional rice cultivars on the in vivo GI.

\section{Materials and methods}

\section{Rice samples}

Four different red pericarp pigmented traditional rice cultivars, namely Kaluheenati, Wedaheenati, Rathkaral and Madathawalu were used for this experiment. Rice samples were obtained from Department of Agriculture, Sri Lanka. They were de-husked using a laboratory dehusker (Model P-1, NgekSengHuat, Thailand). De-husked rice samples were used for the study without any polishing.

\section{Determination of in-vivo glycemic index}

Available carbohydrate of each rice variety was determined by phenol sulfuric colorimetric method [7]. Apparent amylose content (AC) rice flour sample of $100 \mathrm{mg}$ was measured by iodine colorimetric method using a UV-visible spectrometer (Shimadzu, UV-1601, Japan) at $620 \mathrm{~nm}$ [8]. All laboratory experiments were performed in triplicate and the data were expressed in percentage dry basis (d.b. \%).

The method used to measure GI was in line with procedures recommended by the FAO/WHO [9]. Prior to data collection ethical clearance was obtained from the Faculty of Medical Sciences, University of Peradeniya, Sri Lanka. The in-vivo glycemic study was conducted using 12 healthy human subjects (age 22-30 years) having a normal body mass index. Initial fasting blood glucose level was measured using a standardized glucometer (Bene Check ${ }^{\mathrm{TM}}$ PLUS Meter, Germany). Finger-prick blood samples were obtained at 15, 30, 45, 60, 90 and 120 min after the consumption of test rice. As the standard $50 \mathrm{~g}$ of glucose sample was given on a separate morning and blood glucose responses were taken at similar intervals. The GI of rice cultivars for each subject was calculated using the following equation (1). The final GI value is the average GI value of valid participant. Valid results are defined as those within \pm 2 SD of the mean GI value.

${ }^{\star}$ Correspondence to: Batuagahge Don Rohitha Prasantha, Department of Food Science and Technology, Faculty of Agriculture, University of Peradeniya, 20400, Peradeniya, Sri Lanka, Tel: 94718075686; E-mail: rop_bd@yahoo.com

Key words: red rice, rice cultivars, glycemic index, amylose

Received: July 27, 2018; Accepted: August 21, 2018; Published: August 24, 2018 


$$
\mathrm{GI}(\%)=\frac{\text { IAUBG-Rice }}{\text { IAUBG-Glucose }} \times 100
$$

Whereas;

$$
\mathrm{GI}=\text { Glycemic index (\%) }
$$

IAUBG-rice =Incremental area under blood glucose concentration curve of rice

IAUBG-glucose $=$ Incremental area under blood glucose concentration curve of glucose

\section{Statistical analysis}

Amylose and available carbohydrate contents were presented as mean \pm SD (standard deviation) and the GI values as mean \pm SE (standard error). One-way analysis of variance (ANOVA) was performed with all tested parameters. Fisher's least significant difference test (LSD) was used for mean comparisons at $\mathrm{P}<0.05$ [10].

\section{Results and discussion}

The available carbohydrate and amylose contents area showed significant differences $(\mathrm{p}<0.05)$ among the tested rice cultivars. All four rice cultivars showed a high amylose content and available carbohydrate in the range of $26.1-28.5 \%$ and $71.2-74.2 \%$ respectively (Table 1 ). The highest amylose and available carbohydrate contents were observed in Kaluheenati $(28.5 \pm 0.5 \%)$ and Rathkaral $(74.2 \pm 0.6 \%)$ respectively. Rice variety Wedaheenati showed lowest amylose and available carbohydrate contents of $26.1 \pm 0.2 \%$ and $71.2 \pm 0.2 \%$, respectively. Amylose content is the key parameter of cooking and pasting characteristics of rice [9]. In general, soft and slightly moist cooked rice is considered as high-quality rice and these attributes are gained by rice starches with intermediate amylose and moderate gelatinization temperatures $[4,11]$. High amylose $(>25 \%)$, cooked rice has wet-dry and fluffy characteristics and retains its soft texture upon cooling [12].

Generally, there are three categories of foods based their GI values high GI (GI>70), low GI $(\mathrm{GI}<55)$, and intermediate GI $(\mathrm{GI}=56-69 \%)$ foods [13]. The GI of the 4 rice cultivars investigated in the present study ranged from $52.5-64.0 \%$ (Table 1 ). According to this study, there was no significant difference $(\mathrm{p}>0.05)$ in the GI values of tested traditional three rice except Wedaheenati variety $(\mathrm{p}<0.05)$. Although the Wedaheenati can be classified as low GI but it was in the high end of low category. Other three cultivars of Kaluheenati, Rathkaral and Madathawalu can be categorized as medium GI rice cultivars. The Wedaheenati variety exhibited the lowest GI among the other tested cultivars. In contrast to that, Pathiraje et al. [14] reported that GI of full polished Wedaheenati rice was belonged to medium GI category. This difference could be due to the high fiber content of unpolished Wedaheenati rice. Somaratne et al. [2] have reported the negative relationship between the crude fiber

Table 1. Amylose contents (g/ $100 \mathrm{~g}$ dry weight) and glycemic index of red pigmented four traditional rice cultivars

\begin{tabular}{|c|c|c|c|c|c|}
\hline \multirow{2}{*}{ Rice variety } & $\begin{array}{c}\text { Available } \\
\text { carbohydrate } \\
\text { (Mean } \pm \text { SD\%) }\end{array}$ & \multicolumn{2}{|c|}{ Amylose (\%) } & \multicolumn{2}{|c|}{ Glycemic Index (GI) } \\
\cline { 3 - 6 } & Mean \pm SD & Classification & Mean \pm SE & Classification \\
\hline Kaluheenati & $72.1 \pm 0.3^{\mathrm{b}^{*}}$ & $28.5 \pm 0.5^{\mathrm{a}}$ & High & $56.3 \pm 2.5^{\mathrm{a}}$ & Medium \\
\hline Wedaheenati & $71.2 \pm 0.2^{\mathrm{c}}$ & $26.1 \pm 0.2^{\mathrm{c}}$ & High & $52.5 \pm 1.5^{\mathrm{b}}$ & Low \\
\hline Rathkaral & $74.2 \pm 0.6^{\mathrm{a}}$ & $28.0 \pm 0.3^{\mathrm{a}}$ & High & $62.0 \pm 3.1^{\mathrm{a}}$ & Medium \\
\hline Madathawalu & $72.4 \pm 0.5^{\mathrm{b}}$ & $27.2 \pm 0.1^{\mathrm{b}}$ & High & $64.0 \pm 2.5^{\mathrm{a}}$ & Medium \\
\hline
\end{tabular}

$\mathrm{SE}=$ Standard error; $\mathrm{SD}=$ Standard deviation

"Mean $( \pm \mathrm{SE})$ followed by the same superscript within a column are not significantly different $(\mathrm{P}>0.05)$ as measured by the $t$ test. content and GI value of rice. Although the four rice cultivars showed more or less similar high-amylose contents, differences of starch digestion and glycemic response of rice cultivars could be related to their physico-chemical properties [15]. The observed low GI of Wedaheenati variety may perhaps be due to its comparatively low amylose content and available carbohydrate content. The GI values were studied without polishing the pigmented rice, therefore, fiber content may also affect on the GI values of tested rice. According to the previous studies, GI value of brown rice (unpolished) comparatively lower than the full milled white rice $[2,16,17]$. In Sri Lanka, some of the commercial rice cultivars have shown GI values ranging from $67 \%$ to $72 \%$ [18] with the majority of them classified as medium GI rice. According to Hettiarachchi et al. [19] the GI values of Sri Lankan red raw rice varied between 56-73\%. Previously studies have reported that red pigmented less polished rice can effectively control the blood glucose release from the rice starch than white rice [20]. Therefore, consummation of red rice with high fiber content may help to control the type II diabetes prevalence in the country.

\section{Conclusions}

All the four-traditional red pigmented rice cultivars tested in the study belong to high amylose rice. There is no significant difference among the amylose content of the tested rice. Most of the less or unpolished traditional rice cultivars have low-medium GI values are suggested as a better alternative for the regular diet of type 2 diabetes patients.

\section{Ethical approval}

Prior to the study, ethical clearance was obtained from the Faculty of Medicine, University of Peradeniya, Sri Lanka

\section{Acknowledgements}

The volunteers who participated in the study are gratefully acknowledged. Financial and technical assistance was given by the CIC Food and Nutrition Research Centre, Palwehera, Sri Lanka. I also like to extent our sincere gratitude to CIC Food and Nutrition Research Centre and the University of Peradeniya.

\section{References}

1. Prasantha BDR, Hafeel RF, Wimalasiri KMS, Pathirana UPD (2014) End-use quality characteristics of hermetically stored paddy. J Stored Prod Res 59: 158-166.

2. Somaratne GM, Prasantha BDR, Dunuwila GR, Chandrasekara A, Wijesinghe DGNG et al. (2017) Effect of polishing on glycemic index and antioxidant properties of red and white basmati rice. Food Chem 237: 716-723. [Crossref]

3. Jenkins DJ, Kendall CW, Augustin LS, Franceschi S, Hamidi M, et al. (2002) Glycemic index: overview of implications in health and disease. Am J Clin Nutr 76: 266S-73S. [Crossref]

4. Sompong R, Siebenhandl-Ehn S, Linsberger-Martin G, Berghofer E (2011) Physicochemical and antioxidative properties of red and black rice cultivars from Thailand, China and Sri Lanka. Food Chem 124: 132-140.

5. Hettiarachchi HAPW, Rebeira SP, Prasantha BDR, Wickramasinghe HAM (2016) Diversity of Physical and Cooking Quality Characters of Selected Traditional and Improved Rice Cultivars in Sri Lanka. Sri Lankan Journal of Biology 1: 15-26.

6. Abesekara WKSM, Somasiri HPPS, Premakumara GAS, Benthota AP, Rajapakse D, et al. (2008) Cooking and eating quality traits of some Sri Lankan traditional rice cultivars across Yala and Maha seasons. Tropical Agriculture Research 20: 168-176.

7. AACC (2000) Approved Methods of the American Association of Cereal Chemists Methods 14-50 and 44-15A.AACC International, St. Paul, Minnesota, USA.

8. Juliano BO (1971) A Simplified Assay for Milled-Rice Amylose. Cereal Science Today 16: $334-360$. 
9. FAO/WHO (1998) Carbohydrates in human nutrition (FAO Food and Nutrition Paper-66). Report of a Joint FAO/WHO Expert Consultation, Rome 14-18 April 1997. Reprinted 1998. pp 1-140.

10. SAS Institute (19900 SAS language and procedures, version 6.1st edition. SAS Institute, Cary, NC, USA.

11. Wickramasinghe HAM, Noda T (2008) Physicochemical properties of starches from Sri Lankan rice cultivars. Food Sci Technol Res 14: 49-54.

12. Darandakumbura HDK, Wijesinghe DGNG, Prasantha BDR (2013) Effect of processing condition and milling rate on apparent amylose content of locally grown rice verities. Trop Agric Res 24: 317-324.

13. Foster-Powell KF, Holt SHA, Miller JCB (2002) International table of glycemic index and glycemic load values. Am J Clin Nutr 76: 50-56.

14. Pathiraje P, Madhujith W, Chandrasekara A, Nissanka S (2011) The effect of rice variety and parboiling on in vivo glycemic response. Trop Agric Res 22: 26-33.
15. Panlasigui LN, Thompson LU, Juliano BO, Perez CM, Yiu SH, et al. (1991) Rice cultivars with similar amylose content differ in starch digestibility and glycemic response in humans. Am J Clin Nutr 54: 871-877.

16. Panlasigui LN, Thompson LU (2006) Blood glucose lowering effects of brown rice in normal and diabetic subjects. Int J Food Sci Nutr 57: 151-158.

17. Babu PD, Subhasree R, Bhakyaraj R, Vidhyalakshmi R (2009) Brown rice-beyond the color reviving a lost health food-a review. American-Eurasian Journal of Agronomy 2: 67-72.

18. Darandakumbura HDK, Wijesinghe DGNG, Prasantha BDR (2013) Effect of processing conditions and cooking methods on resistant starch, dietary fiber and glycemic index of selected rice cultivars grown in Sri Lanka. Trop Agric Res 24: 163-174.

19. Hettiarachchi P, Jiffry MTM, Jansz ER, Wickramasinghe AR, Fernando DJS (2001) Glycemic indices of different cultivars of rice grown in Sri Lanka. Ceylon Medical Journal 46: 11-14.

20. Perera AS, Jansz ER (2000) Preliminary investigations on the red pigment in rice and its effect on glucose release from rice starch. J Natl Sci Found 28: 185-192.

Copyright: ${ }^{0} 2018$ Prasantha BDR. This is an open-access article distributed under the terms of the Creative Commons Attribution License, which permits unrestricted use, distribution, and reproduction in any medium, provided the original author and source are credited. 